\title{
Effects of the energy density and sweetness of porridges used in the complementary feeding of infants on energy and nutrient intakes
}

\author{
SANDRINE ESTELLE KOUTON ${ }^{1,2}$, WALIOU AMOUSSA HOUNKPATIN ${ }^{2}$, \\ SAM BODJRENOU $^{2}$ and MOHAMED M. SOUMANOU ${ }^{1}$
}

${ }^{1}$ Research Unit in Enzymatic and Food Engineering, Polytechnic School of Abomey-Calavi (EPAC), University of Abomey-Calavi (UAC), 01 BP 2009 Cotonou; ${ }^{2}$ School of Nutrition, Foods Sciences and Technology/Faculty of Agricultural Sciences/University of Abomey-Calavi, 01 BP 526 Cotonou, Benin

Received April 17, 2021; Accepted September 13, 2021

DOI: $10.3892 /$ ijfn.2021.20

\begin{abstract}
In the present study, under free-living conditions, 30 breastfed children, aged 6 to 23 months, were successively fed three complementary porridges in order to examine the effect of energy density (ED) and sweetness on energy and nutrient intake (ENI). Two high ED porridges, such as malted (Fg3, $124.92 \mathrm{kcal})$, fermented (F3, $120.36 \mathrm{kcal})$ and low ED porridge (G1, $60 \mathrm{kcal})$ were consumed. The sucrose content of the high and low ED porridges was 15 and 5\%, respectively. The results revealed that the amount consumed of F3 (282.2 $\mathrm{ml}$ for group 1, 6 to 11 months old; and $365 \mathrm{ml}$ for group 2, 12 to 23 months old) was higher than that of $\mathrm{Fg} 3$ (231.20 and $331.30 \mathrm{ml}$ for groups 1 and 2, respectively) and G1 (105 and $129.10 \mathrm{ml}$ for groups 1 and 2, respectively). Despite the amounts consumed of Fg3, the ENI from Fg3 was higher than that of F3 and G1. The consumption of F3 and Fg3 increased the energy intake (EI) by 74 and $78 \%$, respectively ( 23.25 and 26.56 vs. $5.97 \mathrm{Kcal} / \mathrm{kg} / \mathrm{meal} ; \mathrm{P}<0.001)$ in group 1 and by 78 and $83 \%$, respectively ( 24.37 and 30.82 vs. $5.24 \mathrm{Kcal} / \mathrm{kg} / \mathrm{meal} ; \mathrm{P}<0.001$ ) in group 2 in comparison with the EI from G1. Thus, the consumption of sweet porridge with a high ED (Fg3) composed of local ingredients increased, at least by 78 and $83 \%$, in the infants of group 1 and 2, respectively, the EI from porridges in comparison with the EI from low the ED porridge, G1. The ENI was significantly $(\mathrm{P}<0.001)$ higher with the sweetness and dry matter of porridges than with the low sweetness and dry matter porridge. Consequently, $\mathrm{Fg} 3$ has a high coverage and this permits it to cover $>36 \%$ of
\end{abstract}

Correspondence to: Dr Sandrine Estelle Kouton, Research Unit in Enzymatic and Food Engineering, Polytechnic School of Abomey-Calavi (EPAC), University of Abomey-Calavi (UAC), 01 BP 2009 Cotonou, Benin

E-mail: sandrineskouton@gmail.com

Key words: energy density, sweetness, porridges, intake, requirement daily intake, children daily energy needs, as well as 73,93 and 48\% of daily iron, zinc and calcium needs, respectively.

\section{Introduction}

The complementary feeding (CF) period is critical for a child's growth (1). From the age of 6 months, breast milk intake cannot provide all the energy and the nutrients necessary to meet an infants' nutritional needs. Thus, it is recommended to introduce other foods to complement breast milk in an infant's diet (2). The CF corresponds to the period during which infants are introduced, in a step by step process, to foods other than breast milk, slowly discovering their properties in terms of flavour, texture etc., as well as energy density (ED) (3). During this period, children are particularly vulnerable and a number of factors related to children, mothers and socio-economic conditions of the household contribute to the vulnerability of children during the period of CF (4). In the majority of cases, malnutrition begins during the $\mathrm{CF}$ period, since a number of mothers and caregivers lack knowledge and/or the financial resources to provide adequate foods to young children $(5,6)$. This significantly contributes to the high prevalence of malnutrition in children $<5$ years of age worldwide (7).

During this vulnerable period for infants, it is necessary to introduce complementary foods which contain a high energy and nutrient density, and with diverse organoleptic characteristics in order to increase food intake. These high nutritional and organoleptic qualities of complementary foods improve the energy and nutrient intake (ENI) of infants and this participate an optimal growth of infants in the CF period. Similarly, in low-income countries such as Benin in Sub-Saharan Africa, the $\mathrm{CF}$ practices are also suboptimal $(8,9)$. The complementary porridges have a low energy and nutrient density. Indeed, the complementary foods comprise of local cereals which are flour-based, with or without the addition of water and $\operatorname{sugar}(9,10)$.

In Benin, complementary foods are mostly maize porridge and/or fermented sorghum porridge obtained from recycled maize dough. The protein density of complementary porridge is low $(9,10)$. Poor feeding practices and a shortfall in food 
intake are direct factors responsible for malnutrition and illness among children in Benin (11). These practices, which include the use of complementary foods which with low nutritional values and organoleptic qualities, and the inappropriate conduct of CF practices, partly explain the prevalence of $32 \%$ of stunting observed in pre-school children in Benin (8).

Thus, these inadequate complementary porridges do not have notable organoleptic characteristics (9). The early introduction of complementary foods (before 6 months of age) and the use of complementary foods with low nutritional and organoleptic qualities contribute to inappropriate CF practices, decreasing the appetite of infants and food intake $(3,4)$. In the majority of cases, infants reject the inadequate porridge, and this may lead to low nutrient intake $(4,12)$. Consequently, mothers are obliged to force-feed children in order to ensure that their stomachs are full (11). Therefore, the amount consumed of porridge is low. Consequently, the ENI from these inadequate complementary foods were low. Thus, the children are not able to cover their nutritional needs for optimal growth. Energy intakes (EIs) from porridges are at a low level due to their insufficient ED and their low organoleptic characteristics, as well as due to the fact that the mean quantities of consumed porridges remain far lower than the theoretical infant gastric capacity.

In order to increase the intake of infants, the nutritional and organoleptic qualities of inadequate complementary foods have to be improved $(9,10)$. Thus, mothers should use porridges with a high energy and nutrient density, and adequate fluid consistency (10). Therefore, the use of nutritional and organoleptic adequate complementary foods is a high priority in low-incomes countries (13-15). Researchers recognize that the improvement of the characteristics of complementary foods is crucial for increasing the food intake of infants (5). Indeed,ENI are influenced by a number of factors related to the food itself (viscosity, taste-sweetness, flavour, dry matter content, odour, energy and nutrient densities), to children (stomach capacity, appetite and nutritional status) and to mothers or caregivers (knowledge and CF practices, frequency, during and taking care of the meal) (16). Three factors determine the level of the daily ENI from complementary foods: These are the number of meals per day, the amounts of porridge intake per meal and the energy and nutrient density of food per meal (16). Only the two last factors are intrinsically dependent on the properties of porridge.

Several studies have demonstrated that the incorporation of protein, fruits and vegetables, and the use of traditional process, such as fermentation and malting has improved the nutritional and energy qualities of complementary foods for an optimal growth of infant $(13-15,17)$. Precisely, fermentation is one of the oldest and most economical methods of producing and preserving foods that improves the organoleptic properties of foods by developing a variety in flavours and a high taste (17). Another advantage of fermentation is to increase the nutritional value, probiotics effect for children and the digestibility of foods $(13,17)$. Particularly, the malting of cereal seeds in complementary foods has the advantage of increasing their nutritional value, dry matter and energy density (13). Another advantage of the malting process, is that it improves the bioavailability of certain essential minerals (iron, calcium, zinc) and vitamins for young children (17).
It has been demonstrated that improving the organoleptic characteristics of complementary foods can increase the intake of porridges consumed by children (18). In order to reach these goals, it is pertinent to evaluate the effects of improving the organoleptic characteristics of these complementary porridges on the ENI of infants. Therefore, the organoleptic characteristics of three complementary foods have been improved by the incorporation of different (5 to $15 \%$ ) ratios of sucrose $(17,18)$. The low ED infant cereals (G1) contain only cereals and 5\% sucrose. The fermented (F3) and malted (Fg3) infant cereals have a high ED and contain 15\% of sucrose, respectively. The infant malted flour $(\mathrm{Fg} 3)$ is processed by mixing maize and sorghum malted flours, soybean roasted flour, sucrose and 'baobab' pulp at different ratios. In addition, the infant fermented flour (F3) is processed by mixing maize malted flour, 'Mawè', roasted soybean and sorghum flours, sucrose and baobab pulp. The saccharose contents of the flours are $1.2 \%$ for $\mathrm{G} 1,4.2 \%$ for fermented porridge $\mathrm{F} 3$ and $5.3 \%$ for malted porridge $\mathrm{Fg} 3$ (17).

The aim of the present study was to identify which type of porridge can be used to increase the EIs of infants in Benin. For this purpose, the main factors which influence intake were investigated. The present study was conducted in Southern Benin and focused on factors related to food. The study also examined the effects of ED and the sweetness of the porridges on the EI of infants in Benin aged between 6 to 23 months under free-living conditions. The present study had two objectives: The first one was to demonstrate in this context, the nutritional benefit, i.e., an increase in EI, an increase in porridge dry matter content associated with a decrease in viscosity due to enzymatic treatments with the fermentation and malting process. The second one was to determine whether it is possible to increase the average consumed quantities of high ED porridges and consequently, the EIs from these porridges by modifying their organoleptic characteristics, such as sweetness. The present study, carried out in Southern Benin rural areas, aimed to evaluate the effects of the sweetness and ED of these porridges on the ENI of infants aged 6 to 23 months.

\section{Subjects and methods}

Sampling and selection of participants. The present study was conducted in a village in the district of Adja-Ouèrè (Southern Benin). Sampling was performed in a community health centre. A total of 30 pairs of mother-and-child were randomly selected from the list of mothers attending the health centre and enrolled in the study. The selection criteria were relative to infants and were as follows: i) An age between 6 to 23 months (15 infants were aged 6 to 11 months, and 15 were aged 12 to 23 months) at the beginning of the study; ii) the consumption of the porridges at least twice a day; iii) a weight-for-length $\mathrm{Z}$ score >-3 (not severely wasted) and no particular health issues (no apparent handicaps); and iv) the infants were breastfed. The exclusion criteria were infants that were breastfed but were aged of 0 to 5 months.

Ethical considerations. Local health authorities were informed about the study. For children selected to participate in the study, a consent form was presented and explained to 
the parents (father and mother) in their local language in order to obtain their verbal and written consent. Mothers also gave their consent to participate in the tasting and appreciation of the infant porridges.

Porridges. Three experimental porridges based on a low ED porridge (G1) and two high ED porridges, namely a fermented porridge (F3) and a malted porridge $(\mathrm{Fg} 3)$, were formulated in the laboratory at the Research Unit in Enzymatic and Food Engineering, Polytechnic School of Abomey-Calavi. The three experimental porridges were analysed and tested. The composition of each of the porridges was as follows (Table I): i) G1 resembled the usual porridge prepared by mothers and was based on roasted maize flour and sucrose; ii) $\mathrm{Fg} 3$ was composed of malted maize and sorghum, roasted soybeans, sucrose and baobab pulp; and iii) F3 was a fermented porridge mainly based on fermented maize flour, roasted sorghum and soybeans, sucrose and baobab pulp.

Nutritional and rheological profile of the experimental infant porridges. The nutritional profile and ED assessment of the experimental porridges were determined using recommended methods. The samples were analysed for viscosity, dry matter, protein, saccharose and ED. These characteristics were determined following the methods described by the Association of Official Analytical Chemists (19). The energy value was calculated according to the equation of Atwater and Benedict (20). The viscosity of the experimental porridges was measured using a Bostwick Consistometer (CSC Scientific Company Inc.) according to the method of (21). The flow distance was used at the usual temperature of consumption $\left(45^{\circ} \mathrm{C}\right)$, in a Bostwick Consistometer (CSC Scientific Company Inc.) at the Research Unit in Enzymatic and Food Engineering, Polytechnic School of Abomey-Calavi (21) to characterise the consistency of the porridges.

Experimental procedure. Two groups of children were formed for the experiment. Group 1 was composed of 15 infants aged 6 to 11 months and group 2 was composed of 15 infants aged 12 to 23 months. Each group of children was provided with the three (G1, F3 and Fg3) experimental porridges, one porridge per day for a period of 3 days, at the usual porridge feeding time (12 p.m.). Porridges were prepared and packaged in the laboratory at the Research Unit in Enzymatic and Food Engineering, Polytechnic School of Abomey-Calavi under sanitary conditions. The quantity of water necessary to prepare the porridge, was weighed and added to pre-weighed flour. The porridges were cooked for $5 \mathrm{~min}$. The children were fed by their mothers or by their usual caregivers. The amount of porridge consumed was measured, by weighing the bowl before (bowl and served porridge) and after feeding (bowl + remaining porridge) using an electronic scale (Tefal; maximum, $5 \mathrm{~kg}$; precision, $1 \mathrm{~g}$ ). The acceptability of the porridges by the infants was evaluated using the amounts of porridge consumed by the infants. Only the amounts of porridge consumed with sucrose were used for the determination of the ENI of the infants. The ENIs were determined by calculations using the information for the nutritional value of each porridge (17). The following factors were considered: Energy, lipids, proteins, iron, calcium, zinc and magnesium. The weight and sex of each child were used to determine their ENI. For each child, the ratio from the ENI for children and their daily nutrient intake requirements were determined. This ratio was used to determine the effectiveness of the porridges to fully provide the daily nutrient intake requirements of children (22-26). The contribution of high ED porridges in increasing the ENI of infants in comparison with the low ED porridge was determined by the ratio between the differences of the means of ENI of the high and low ED porridges, and the means of ENI of the high ED porridges (27). The recommended daily intake (RDI) of children aged 6 to 8 months was higher than that of infants aged $>8$ months. Indeed, the coverage of the RDI of infants was presented in two groups as the respective RDI of group 1 (children aged 6 to 8 months, and 8 to 11 months) and of group 2 (children aged 12 to 23 months).

Statistical analysis. Data were analysed using Statistica 7.1 (17) (https://statistica.software.informer.com). Two-way analysis of variance (ANOVA) was used to determine whether there was an effect of the porridge characteristics on the food intake of the infants. The variables included in the statistical model were the amounts of porridge consumed and the type of porridge (low and high energy value). The analysis of the data followed a normal distribution. Following ANOVA, the Student-Newman-Keuls test was performed to compare the amounts of porridge consumed and the ENI according to the type of porridge.

\section{Results}

Characteristics of the porridges. The nutritional characteristics of the experimental porridges are presented in Table II. Due to the low dry matter content, the G1 porridge had a markedly lower lipid, protein and carbohydrate content than the high ED porridges, F3 and Fg3. The viscosity of the experimental porridges was measured by the flow distance of the porridges at the usual temperature of consumption $\left(45^{\circ} \mathrm{C}\right)$ using a Bostwick Consistometer. A low viscosity was characterized by the high flow distance of the porridges on the Bostwick Consistometer. The experimental high ED porridges, F3 and Fg3, had a flow distance on the consistometer at 110 and $155 \mathrm{~mm} / 30 \mathrm{sec}$, respectively. The flow distance on the consistometer of the low ED (G1) porridge was $35 \mathrm{~mm} / 30 \mathrm{sec}$. Indeed, the malted porridge, $\mathrm{Fg} 3$, had a lower viscosity than the other porridges. The saccharose content of the three porridges was 1.2, 4.2 and $5.3 \%$ for the low ED porridge $(\mathrm{G} 1)$, the high ED fermented porridge (F3) and the high ED malted porridge (Fg3), respectively. The saccharose content of the $\mathrm{Fg} 3$ porridge was higher than that of F3 and G1. Thus, the saccharose content of the experimental porridges was appropriate for $\mathrm{CF}$ based on the WHO recommendations (2).

Infants. In the study area, all the children eligible to participate in the study were registered. Given their low number, all of them were enrolled in the study. A total of 17 male and 13 female infants participated in the study. The characteristics of the children included in the study are presented in Table III.

Amount of porridges consumed by the infants. Following the analysis, it was found that the amount of G1 porridge consumed 
Table I. Composition of $100 \mathrm{~g}$ of the cereals.

\begin{tabular}{|c|c|c|c|c|c|c|c|c|}
\hline $\begin{array}{l}\text { Infant } \\
\text { flours }\end{array}$ & $\begin{array}{l}\text { Roasted } \\
\text { maize flour }\end{array}$ & $\begin{array}{l}\text { Germinated } \\
\text { maize flour }\end{array}$ & $\begin{array}{l}\text { Germinated } \\
\text { sorghum flour }\end{array}$ & $\begin{array}{l}\text { 'Mawè' } \\
\text { flour }\end{array}$ & $\begin{array}{c}\text { Roasted } \\
\text { sorghum flour }\end{array}$ & $\begin{array}{c}\text { Roasted } \\
\text { soybeans flour }\end{array}$ & Sucrose & $\begin{array}{l}\text { Baobab } \\
\text { pulp }\end{array}$ \\
\hline G1 & 95 & - & - & - & - & - & 5 & - \\
\hline $\mathrm{Fg} 3$ & - & 30 & 25 & - & - & 25 & 15 & 5 \\
\hline F3 & - & 4 & - & 30 & 21 & 25 & 15 & 5 \\
\hline
\end{tabular}

The quantity of ingredients is presented (g/100 g). Mawè, fermented maize flour; G1, low energy density porridge; Fg3, high energy density malted porridge; F3, high energy density fermented porridge.

Table II. Characteristics of the experimental porridges.

Characteristic

\begin{tabular}{lccccc}
\cline { 2 - 5 } Porridge & Viscosity $(\mathrm{mm} / 30 \mathrm{sec})$ & Dry matter $(\%)$ & Protein $(\%)$ & Energy density $(\mathrm{kcal} / 100 \mathrm{ml})$ & Saccharose $(\%)$ \\
\hline G1 & $35 \pm 5^{\mathrm{c}}$ & $15 \pm 0.12^{\mathrm{c}}$ & $2.60 \pm 0.03^{\mathrm{c}}$ & $60 \pm 0.48^{\mathrm{c}}$ & $1.2 \pm 0.02^{\mathrm{c}}$ \\
Fg3 & $155 \pm 3^{\mathrm{a}}$ & $31.23 \pm 0.8^{\mathrm{a}}$ & $16.65 \pm 1.2^{\mathrm{a}}$ & $124.92 \pm 1.8^{\mathrm{a}}$ & $5.3 \pm 0.03^{\mathrm{a}}$ \\
F3 & $110 \pm 5^{\mathrm{b}}$ & $30.09 \pm 0.8^{\mathrm{b}}$ & $15.32 \pm 0.3^{\mathrm{b}}$ & $120.36 \pm 1.8^{\mathrm{b}}$ & $4.2 \pm 0.02^{\mathrm{b}}$ \\
\hline
\end{tabular}

G1, low energy density porridge; Fg3, high energy density malted porridge; F3, high energy density fermented porridge. In same column, the different letters $(a-c)$ indicate significant differences between the different porridges $(\mathrm{P}<0.05)$.

was low, whereas the amount of F3 porridge consumed was higher than that of the $\mathrm{G} 1$ and $\mathrm{Fg} 3$ porridges. In the present study, the amount of porridges consumed by the two groups (group 1 and 2) of infants were compared. The amount of porridges consumed differed significantly with the age of the infants $(\mathrm{P}=0.001)$ and the type of porridge (Table IV). The amount consumed of porridges ranged from 105 (G1) to $365 \mathrm{ml}$ (F3). The amount of porridge consumed in group 2 was significantly higher than that in group 1 . In one meal, the amount of porridges consumed in group 1 was $105,231.20$ and $282.2 \mathrm{ml}$ for the G1, Fg3 and F3 porridges, respectively. The amount of porridges consumed in group 2 was 129.10, 331.30 and $365 \mathrm{ml}$ for the G1, Fg3 and F3 porridges, respectively (Table IV). In the two groups of infants, the amount of G1 porridge consumed was low, whereas the amount of F3 porridge consumed (282.2 $\mathrm{ml}$ in group 1 and $365 \mathrm{ml}$ in group 2) was higher than that of the Fg3 (231.20 and $331.3 \mathrm{ml}$ in groups 1 and 2, respectively) and G1 porridges (105 and $129.1 \mathrm{ml}$ in groups 1 and 2, respectively).

ENI from porridges during a meal. The ENI from the porridges in the two groups of infants was determined (Tables V and VI). The ENI from the porridges differed significantly with the age of the infant $(\mathrm{P}=0.001)$ and the type of porridge. The ENI in group 2 was significantly higher than that in group 1. The ENI from the low ED porridge G1 was low. In one meal, the ENI from the high ED porridges (Fg3 and F3) was significantly higher than that from the low ED porridge (G1). Precisely, the ENI of the malted porridge (Fg3) was higher than that of the fermented porridge (F3) and the low ED porridge (G1). Therefore, the EI ranged from 54.08 (G1) to $344.37 \mathrm{Kcal}$ (Fg3) in both groups. The EI in group 1 was $54.08,210.47$ and $240.37 \mathrm{Kcal}$ for the G1, F3 and $\mathrm{Fg} 3$ porridges, respectively. The EI in group 2 was 58.64 , 272.28 and $344.37 \mathrm{Kcal}$ for the G1, F3 and Fg3 porridges, respectively (Table V).

In one meal, from the amounts consumed, the consumption of the high ED porridges ( $\mathrm{F} 3$ and $\mathrm{Fg} 3$ ) increased the EI in group 1 by $74 \%\{[(23.25-5.97) / 23.25] \times 100=74.32 \%\}$ and $78 \%\{[(26.56-5.97) / 26.56] \times 100=77.52 \%\}$ in comparison with the EI from the low ED porridge (G1) (23.25 and 26.56 vs. $5.97 \mathrm{Kcal} / \mathrm{kg} / \mathrm{al} ; \mathrm{P}<0.05)$. The high ED porridges ( $\mathrm{F} 3$ and $\mathrm{Fg} 3$ ) increased the EI in group 2 by 78 and $83 \%$ in comparison with the EI from low ED porridge (G1) (24.37 and 30.82 vs. $5.24 \mathrm{Kcal} / \mathrm{kg} / \mathrm{meal} ; \mathrm{P}<0.001)$ (Table V).

The dry matter of the high ED fermented (F3) and malted (Fg3) porridges was 30.09 and $31.23 \%$, respectively. The low ED porridge (G1) had $15 \%$ dry matter. Thus, the high ED porridges had a higher dry matter than the low ED porridge (G1). The high ED fermented (F3) and malted (Fg3) porridges contained $15 \%$ sucrose, and 4.2 and $5.3 \%$ saccharose, respectively. The high ED porridges ( $\mathrm{F} 3$ and $\mathrm{Fg} 3$ ) were sweeter than the low ED porridge (G1), which contained $1.2 \%$ saccharose (Table II). Thus, the EI was significantly $(\mathrm{P}<0.05)$ higher with the sweeter porridges than with the less sweet porridge $(\mathrm{G} 1)$ (Table V). The improvement in EI was greater with the higher sugar content.

In one meal, the mineral intake from the high ED porridge (Fg3) was higher than that of the fermented porridge (F3) and the low ED porridge (G1). The iron intake ranged from 1.49 (G1) to $11.86 \mathrm{~g}(\mathrm{Fg} 3)$ in both groups. The calcium intake ranged from $44.50(\mathrm{G} 1)$ to $255.70 \mathrm{~g}(\mathrm{Fg} 3)$ and the zinc intake ranged from $1.63(\mathrm{G} 1)$ to $9.15 \mathrm{~g}(\mathrm{Fg} 3)$ in both groups. The magnesium intake also ranged from $12.37(\mathrm{G} 1)$ to $73.11(\mathrm{Fg} 3)$ in both groups. 
Table III. Characteristics of the children included in the study.

\begin{tabular}{|c|c|c|c|c|}
\hline Group of children & Child & Sex & Age (months) & Weight (kg) \\
\hline \multirow[t]{15}{*}{ Group 1: Children aged 6 to 11 months $(n=15)$} & 1 & $\mathrm{~F}$ & 7 & 8.03 \\
\hline & 2 & M & 8 & 8.62 \\
\hline & 3 & M & 8 & 8.62 \\
\hline & 4 & $\mathrm{~F}$ & 9 & 8.55 \\
\hline & 5 & $\mathrm{~F}$ & 9 & 8.55 \\
\hline & 6 & M & 10 & 9.37 \\
\hline & 7 & M & 10 & 9.37 \\
\hline & 8 & $\mathrm{~F}$ & 10 & 8.78 \\
\hline & 9 & M & 10 & 9.37 \\
\hline & 10 & M & 11 & 9.62 \\
\hline & 11 & $\mathrm{~F}$ & 11 & 9 \\
\hline & 12 & $\mathrm{~F}$ & 11 & 9 \\
\hline & 13 & M & 11 & 9.62 \\
\hline & 14 & M & 11 & 9.62 \\
\hline & 15 & $\mathrm{M}$ & 11 & 9.62 \\
\hline \multirow[t]{15}{*}{ Group 2: Children aged 12 to 23 months $(n=15)$} & 1 & $\mathrm{~F}$ & 12 & 10.8 \\
\hline & 2 & $\mathrm{~F}$ & 12 & 10.8 \\
\hline & 3 & $\mathrm{~F}$ & 12 & 10.8 \\
\hline & 4 & $\mathrm{~F}$ & 13 & 10.8 \\
\hline & 5 & M & 14 & 11.5 \\
\hline & 6 & M & 15 & 11.5 \\
\hline & 7 & M & 15 & 11.5 \\
\hline & 8 & M & 16 & 11.5 \\
\hline & 9 & M & 18 & 11.5 \\
\hline & 10 & $\mathrm{~F}$ & 18 & 10.8 \\
\hline & 11 & $\mathrm{M}$ & 18 & 11.5 \\
\hline & 12 & $\mathbf{M}$ & 20 & 11.5 \\
\hline & 13 & $\mathrm{~F}$ & 20 & 10.8 \\
\hline & 14 & $\mathrm{~F}$ & 22 & 10.8 \\
\hline & 15 & $\mathrm{M}$ & 22 & 11.5 \\
\hline
\end{tabular}

M, male; F, female.

In one meal, from the amounts consumed, the consumption of the high ED porridges (F3 and Fg3) increased the iron intake in group 1 by $78 \%\{[(6.82-1.49) / 6.82] \times 100=78.15 \%\}$ and $82 \%$ $\{[(8.27-1.49) / 8.27] \times 100=81.98 \%\}$, respectively in comparison with the iron intake from the low ED porridge (G1) $(6.82$ and 8.27 vs. $1.49 \mathrm{mg} / \mathrm{meal}$; $\mathrm{P}<0.05)$. The high ED porridges ( $\mathrm{F} 3$ and $\mathrm{Fg} 3$ ) increased the iron intake in group 2 by 71 and $78 \%$, respectively in comparison with the iron intake from the low ED porridge (G1) $(8.82$ and 11.86 vs. $2.57 \mathrm{mg} / \mathrm{meal}$; $\mathrm{P}<0.05$. In one meal, from the amounts consumed, the consumption of the high ED porridges (F3 and $\mathrm{Fg} 3$ ) increased the calcium intake in group 1 by 68 and 75\%, respectively in comparison with the calcium intakes from low ED porridge (G1) (138.94 and 178.48 vs. $44.50 \mathrm{mg} / \mathrm{meal}$; $\mathrm{P}<0.05)$. The high $\mathrm{ED}$ porridges ( $\mathrm{F} 3$ and $\mathrm{Fg} 3$ ) increased the calcium intake in group 2 by 72 and $80 \%$, respectively in comparison with the calcium intake from the low ED porridge (G1) (179.74 and 255.70 vs. $51.15 \mathrm{mg} / \mathrm{meal}$; $\mathrm{P}<0.05)$. The mineral intake was significantly $(\mathrm{P}<0.05)$ higher with the sweetest high ED porridges (Fg3 and F3) than with the less sweet porridge (G1). The improvement in mineral intake was greater with the higher sugar content (Table VI).

Coverage of daily intake requirement from the porridges during a meal. The contribution of the high ED porridges ( Fg3 and F3) to the coverage of the daily intake requirements were differed significantly with the group of infants (Table VII). The coverage of the daily intake requirement from the low ED porridge G1 was low. The coverage of the daily intake requirement from the high ED malted porridge (Fg3) was higher than that of the fermented porridge (F3) and the low ED porridge (G1). The consumption of the $\mathrm{F} 3$ and $\mathrm{Fg} 3$ porridges contributed to providing $>30$ and $36 \%$, respectively of the daily energy intake requirements and $>77$ and $95 \%$, respectively of the daily protein intake requirements. Precisely, the consumption of the malted porridge $(\mathrm{Fg} 3)$ covered $>36 \%$ of the daily EI requirements for the children aged 6 to 23 months. The mineral intakes from the high ED porridges (F3 and Fg3) contributed to covering 56 and $73 \%$, respectively of the daily iron intake 
Table IV. Means amounts of porridges consumed $(\mathrm{ml})$ by infants during a meal.

Amount of porridge consumed $(\mathrm{ml})$

Age (months)

Stomach capacity $(\mathrm{ml})$

G1

$\mathrm{Fg} 3$

F3
Group 1: 6-11 months old $(n=15)$

285

$105 \pm 4.5^{\mathrm{c}}$

$231.2 \pm 45.5^{\mathrm{b}}$

$282.2 \pm 42.3^{\mathrm{a}}$
Group 2: 12-23 months old $(\mathrm{n}=15)$ 345

$129.1 \pm 12.6^{c}$

$331.3 \pm 19.0^{\mathrm{b}}$

$365 \pm 29.3^{a}$

G1, low energy density porridge; Fg3, high energy density malted porridge; F3, high energy density fermented porridge. In the same column, the different letters $(\mathrm{a}-\mathrm{c})$ indicate significant differences between the different porridges in the same group $(\mathrm{P}<0.05)$. In same row, the mean of each porridge between group 1 and group 2 differed significantly $(\mathrm{P}<0.05)$.

Table V. Mean energy intake from the porridges during a meal.

\begin{tabular}{lccccc}
\hline & \multicolumn{4}{c}{ Energy intake from porridge (Kcal) } \\
\cline { 2 - 3 } & \multicolumn{2}{c}{ Mean(kcal/meal) } & \multicolumn{2}{c}{ Mean (kcal/kg/meal) } \\
\cline { 2 - 3 } \cline { 5 - 6 } Porridge & $\begin{array}{c}\text { Group 1: 6-11 months } \\
\text { old (n=15) }\end{array}$ & $\begin{array}{c}\text { Group 2: 12-23 months } \\
\text { old (n=15) }\end{array}$ & & $\begin{array}{c}\text { Group 1: 6-11 months } \\
\text { old (n=15) }\end{array}$ & $\begin{array}{c}\text { Group 2: 12-23 months } \\
\text { old (n=15) }\end{array}$ \\
\hline G1 & $54.08 \pm 3.71^{\mathrm{c}}$ & $58.64 \pm 2.97^{\mathrm{c}}$ & & 5.97 & 5.24 \\
F3 & $210.47 \pm 32.73^{\mathrm{b}}$ & $272.28 \pm 22.66^{\mathrm{b}}$ & & 23.25 & 24.37 \\
Fg3 & $240.37 \pm 48.97^{\mathrm{a}}$ & $344.37 \pm 20.47^{\mathrm{a}}$ & & 26.56 & 30.82 \\
\hline
\end{tabular}

G1, low energy density porridge; Fg3, high energy density malted porridge; F3, high energy density fermented porridge. In the same column, the different letters $(\mathrm{a}-\mathrm{c})$ indicate significant differences between the different porridges in the same group $(\mathrm{P}<0.05)$. In the same row, the mean of each porridge between group 1 and group 2 was differed significantly $(\mathrm{P}<0.05)$.

requirements, 65 and $93 \%$, respectively of the daily zinc intake requirement, 35 and $48 \%$, requirement of the daily calcium intake requirement, and 82 and $>100 \%$ of the daily magnesium intake requirement for infants aged 6 to 23 months. The coverage of the daily intake requirement was low for children aged 6 to 8 months, as their daily intake requirement at this age is higher than that of infants aged $>8$ months (Table VII).

\section{Discussion}

The amount of porridges consumed were differed significantly with the age of the infant and the type of porridge $(\mathrm{P}=0.001)$. The results revealed that the amounts of porridges consumed in group 2 were significantly higher than those in group 1 . The gastric capacity (345) of the infants in group 2 was higher than that $(285 \mathrm{ml})$ of the infants of group 1 . The amount of G1 porridge consumed was low. The amounts of the high ED porridges ( $\mathrm{F} 3$ and $\mathrm{Fg} 3$ ) consumed were higher than those of the low ED porridge (G1), whereas the amount of the fermented $\mathrm{F} 3$ porridge consumed was higher than that of the Fg3 and G1 porridges.

These results indicated that the fermented porridge F3 was the one most appreciated by the infants. This high appreciation was due to the organoleptic characteristics. These organoleptic characteristics of the fermented F3 porridge are due to the fermentation process, which can enhance these characteristics. Particularly, fermentation is one of the oldest and most economical methods for producing and preserving foods that improves the organoleptic properties of foods by leading to a variety in flavours and a high taste (27). Another advantage of fermentation is to increase the nutritional value, probiotics effect for children and the digestibility of foods $(13,17,27)$.

From the amounts of porridge consumed, the ENI from the low ED porridge (G1) was low. The ENI in group 2 was significantly higher than that in group 1 . In one meal, the ENI from the high ED porridges (Fg3 and F3) was significantly higher than that from the low ED porridge (G1). Despite the lower amount of malted porridge $\mathrm{Fg} 3$ consumed in comparison with that of the fermented porridge F3, the ENI of the malted porridge $\mathrm{Fg} 3$ was higher than that of the fermented porridge F3 and the low ED porridge G1. This result was evidenced by the fact that the dry matter and sweetness of the $\mathrm{Fg} 3$ porridge were higher than those of F3 and G1 porridges.

The dry matter of the high ED fermented (F3) and malted (Fg3) porridges was 30.09 and $31.23 \%$, respectively. In addition, the malted porridge Fg3 had a higher dry matter than that of the fermented F3 porridge and the low ED porridge (G1), which had $15 \%$ dry matter. The high ED fermented (F3) and malted (Fg3) porridges contained 15\% sucrose, and 4.2 and $5.3 \%$ saccharose, respectively. The malted Fg3 
porridge was sweeter than the fermented $\mathrm{F} 3$ porridge and the G1 porridge. The EI was significantly higher $(\mathrm{P}<0.001)$ with the sweeter porridges than with the less sweet porridge G1. The improvement in EI was greater with the higher sugar content. Consequently, the results indicated that the ENI was significantly higher from the porridge with a higher dry matter content and a greater sweetness.

One of the consequences of increasing the dry matter content of porridges was the increase in their sweetness. For this reason, these results indicated that effect of ED and the sweetness of the complementary porridges on the EI of the Beninese infants under free-living conditions improved the EI from the porridge feedings.

Studies in Burkina-Faso demonstrated that the addition of sucrose to improve the ED and taste of porridges allowed for an increase in porridge intake (16-18). Researchers have also demonstrated that the high ED porridges containing 9 to $20 \%$ sucrose allow for an increase in the amount of porridges consumed than the low ED porridges, which contain $1 \%$ sucrose (18). A number of researchers have argued that the energy and nutrient density of complementary foods and sweetness are factors which improve food intake (16-18). During CF, infants and children are introduced to foods other than milk. In this sense, they will discover, in a step-by-step process, the properties of foods in terms of flavour, texture, as well as ED. They develop the ability to recognize high and low energy dense complementary foods and sweet food (3). Therefore, the improvement of nutritional and organoleptic characteristics of complementary foods increases the appetite of the infant during a meal and consequently, participates in increasing food intake $(28,29)$.

In the present study, despite a low amount consumed, the high ED porridges ( $\mathrm{F} 3$ and $\mathrm{Fg} 3$ ) increased the $\mathrm{EI}$ in group 1 by 74 and $78 \%$, respectively in comparison with the EI from the low ED porridge G1 (23.25 and 26.56 vs. $5.97 \mathrm{Kcal} / \mathrm{kg} / \mathrm{meal}$; $\mathrm{P}<0.001)$. The high ED porridges ( $\mathrm{F} 3$ and $\mathrm{Fg} 3$ ) increased the EI in group 2 by 78 and $83 \%$, respectively in comparison with the EI from the low ED porridge G1 (24.37 and 30.82 vs. $5.24 \mathrm{Kcal} / \mathrm{kg} / \mathrm{meal}$; $\mathrm{P}<0.001)$. The EI from the malted porridge $\mathrm{Fg} 3$ was higher than that of the fermented porridge F3. Their EIs were 78 and 83\%, respectively for the infants in groups 1 and 2 .

The enhancement of the flavour and taste of the high ED porridges allows for the concomitant increase in the amounts of the porridges consumed and the ENI. The results of the present study were comparable to those of a previous study (18), demonstrating that the intake of high ED porridges which contain between 9 to 20\% sugar allows for an increase of at least $76 \%$ in the EI of infants of 6 to 10 months old. Researchers have demonstrated a similar result at Burkina-Faso, where the improvement of the taste of high energy and nutrient dense porridges by the addition of sugar allows for an increase in the EI of infants aged 6 to 23 months (27). Similar effects of ED porridges on EI have been previously demonstrated $(30,31)$. The results of a previous study (3) also demonstrated that high energy complementary foods and their sweetness characteristics were factors which increased the intake and concomitantly, the energy and nutrient needs during a meal. Similar results were also provided by another study (32), in which the enhancement of flavour and the taste of complementary foods, 
Table VII. Percentage of coverage of daily nutrient intake requirements by the porridges during a meal.

Age of infants (months)

\begin{tabular}{|c|c|c|c|c|}
\hline \multirow[b]{3}{*}{ Nutrient and porridge } & \multirow{2}{*}{\multicolumn{2}{|c|}{ Group 1}} & & \\
\hline & & & \multirow{2}{*}{$\begin{array}{l}\text { Group } 2 \\
12 \text { to } 23\end{array}$} & \multirow[b]{2}{*}{6 to 23} \\
\hline & 6 to 8 & 9 to 11 & & \\
\hline \multicolumn{5}{|c|}{ Energy $(\%)$ from porridges } \\
\hline Fg3 & $27.74 \pm 8.80^{\mathrm{a}}$ & $34.54 \pm 4.71^{\mathrm{a}}$ & $37.96 \pm 2.88^{\mathrm{a}}$ & $35.57 \pm 5.24^{\mathrm{a}}$ \\
\hline F3 & $24.68 \pm 1.42^{\mathrm{a}}$ & $30.22 \pm 3.30^{\mathrm{b}}$ & $29.97 \pm 2.34^{\mathrm{b}}$ & $29.54 \pm 3.11^{\mathrm{b}}$ \\
\hline G1 & $11.83 \pm 1.36^{\mathrm{b}}$ & $16.85 \pm 3.43^{\mathrm{c}}$ & $21.79 \pm 1.08^{\mathrm{c}}$ & $18.82 \pm 4.04^{\mathrm{c}}$ \\
\hline \multicolumn{5}{|c|}{ Protein $(\%)$ from porridges } \\
\hline $\mathrm{Fg} 3$ & $66.82 \pm 21.57^{\mathrm{a}}$ & $84.37 \pm 11.42^{\mathrm{a}}$ & $108.38 \pm 7.34^{\mathrm{a}}$ & $94.62 \pm 18.14^{\mathrm{a}}$ \\
\hline F3 & $58.22 \pm 3.74^{\mathrm{a}}$ & $72.38 \pm 7.70^{\mathrm{b}}$ & $83.95 \pm 6.44^{\mathrm{b}}$ & $76.75 \pm 10.66^{b}$ \\
\hline G1 & $26.43 \pm 3.20^{\mathrm{b}}$ & $38.22 \pm 7.72^{\mathrm{c}}$ & $57.77 \pm 2.49^{\mathrm{c}}$ & $46.81 \pm 12.73^{\mathrm{c}}$ \\
\hline \multicolumn{5}{|l|}{ Iron $(\%)$ from porridges } \\
\hline $\mathrm{Fg} 3$ & $34.39 \pm 12.13^{\mathrm{a}}$ & $47.04 \pm 6.56^{\mathrm{a}}$ & $102.26 \pm 6.08^{\mathrm{a}}$ & $73.38 \pm 30.33^{\mathrm{a}}$ \\
\hline F3 & $28.54 \pm 2.88^{\mathrm{a}}$ & $38.70 \pm 4.17^{\mathrm{b}}$ & $76.06 \pm 6.33^{\mathrm{b}}$ & $56.36 \pm 20.89^{b}$ \\
\hline G1 & $5.51 \pm 0.86^{\mathrm{b}}$ & $8.68 \pm 1.78^{c}$ & $22.21 \pm 1.01^{\mathrm{c}}$ & $15.12 \pm 7.38^{c}$ \\
\hline \multicolumn{5}{|l|}{ Zinc (\%) from porridges } \\
\hline Fg3 & $58.76 \pm 20.72^{\mathrm{a}}$ & $80.38 \pm 11.20^{\mathrm{a}}$ & $110.28 \pm 6.56^{\mathrm{a}}$ & $93.17 \pm 20.97^{\mathrm{a}}$ \\
\hline F3 & $43.50 \pm 4.39^{\mathrm{a}}$ & $58.98 \pm 6.35^{\mathrm{b}}$ & $73.17 \pm 6.09^{b}$ & $64.53 \pm 11.47^{\mathrm{b}}$ \\
\hline G1 & $13.31 \pm 2.08^{\mathrm{b}}$ & $20.97 \pm 4.31^{\mathrm{c}}$ & $33.87 \pm 1.54^{\mathrm{c}}$ & $26.65 \pm 8.20^{\mathrm{c}}$ \\
\hline \multicolumn{5}{|c|}{ Calcium (\%) from porridges } \\
\hline $\mathrm{Fg} 3$ & $34.47 \pm 12.16^{\mathrm{a}}$ & $47.16 \pm 6.57^{\mathrm{a}}$ & $51.14 \pm 3.04^{\mathrm{a}}$ & $47.88 \pm 7.44^{\mathrm{a}}$ \\
\hline F3 & $27.04 \pm 2.73^{\mathrm{a}}$ & $36.66 \pm 3.95^{\mathrm{b}}$ & $35.95 \pm 2.99^{\mathrm{b}}$ & $35.34 \pm 4.33^{\mathrm{b}}$ \\
\hline G1 & $8.46 \pm 1.32^{\mathrm{b}}$ & $13.34 \pm 2.74^{\mathrm{c}}$ & $68.30 \pm 0.00^{\mathrm{c}}$ & $14.69 \pm 3.29^{\mathrm{c}}$ \\
\hline \multicolumn{5}{|c|}{ Magnesium (\%) from porridges } \\
\hline $\mathrm{Fg} 3$ & $73.01 \pm 25.75^{\mathrm{a}}$ & $99.88 \pm 13.92^{\mathrm{a}}$ & $123.69 \pm 9.02^{\mathrm{a}}$ & $109.10 \pm 20.94^{\mathrm{a}}$ \\
\hline F3 & $58.66 \pm 5.93^{\mathrm{b}}$ & $79.54 \pm 8.56^{\mathrm{b}}$ & $88,92 \pm 6,49^{\mathrm{b}}$ & $82.14 \pm 11.58^{\mathrm{b}}$ \\
\hline G1 & $15.69 \pm 2.45^{\mathrm{c}}$ & $24.73 \pm 5.08^{c}$ & $36.02 \pm 1.64^{\mathrm{c}}$ & $29.47 \pm 7.91^{\mathrm{c}}$ \\
\hline
\end{tabular}

G1, low energy density porridge; Fg3, high energy density malted porridge; F3, high energy density fermented porridge. In the same column, the different letters $(\mathrm{a}-\mathrm{c})$ indicate significant differences between the different porridges in the same group $(\mathrm{P}<0.05)$. In the same row, the percentage of coverage of daily nutrient intake requirements of each porridge between group 1 and group 2 differed significantly $(\mathrm{P}<0.05)$.

such as vegetable puree increased acceptance, food intake and concomitantly, the energy and nutrient needs of infant aged 10 to 18 months. Other researchers have demonstrated that the improvement of the nutritional and organoleptic characteristics of complementary foods increases the reaction and appetite of infants during a meal and participates in increasing the quantity of food intake, as well as the ENI (28). Similar results have also been demonstrated by other researchers, whereby the enhancement of the characteristics of complementary foods, such as taste and flavour, increases the food intake (lipids and proteins) by infants aged 6 to 23 months (5). The consumption of high ED porridge could be assumed to improve the total daily energy intake of infants. However, previous studies have observed a phenomenon of energy compensation in infants who balanced energy intake from the different meals consumed during the day and arrived at consistent daily total EIs (4-33). The caloric compensation in infants is dependent on the individual nature of the infant, the type and diversity of the complementary foods, the interaction of mother-infant pairs and the comportment of the infant during a meal (3). In the present study, the EI of the malted porridge $\mathrm{Fg} 3$ was significantly higher than that the fermented porridge F3. This potential of malting porridge $\mathrm{Fg} 3$ is due to an enzymatic treatment malting process; the production of alpha amylase during the germination of cereals decreases the viscosity of porridges, and increases dry matter, the energy and nutritional value of the malted porridge $\mathrm{Fg} 3$, by germination of the local ingredient (17). The malting of cereals is a processing procedure traditionally used in a number of African countries for the manufacture of alcoholic drinks, juices and malted drinks (34). The malting of cereal in complementary foods has the advantage of increasing their nutritional value, dry matter and ED (13). Another advantage of the malting process, is that it improves the bioavailability of certain essential minerals (iron, calcium and zinc) and vitamins for young children (17).

In the present study, the coverage of daily nutrient requirements from the complementary porridges differed significantly with the age of the infants and the type of complementary 
porridge. The coverage of daily intake requirements from the low ED porridge G1 was low. The coverage of daily intake requirements from the high ED malted porridge Fg3 was higher than that of the fermented porridge F3 and the low ED porridge G1. In infants aged 6 to 11 months, the daily energy intake requirements defined (23) are $\sim 79 \mathrm{kcal} / \mathrm{kg} / \mathrm{day}$ and research conducted in different countries have demonstrated that breast milk covers $\sim 60 \%$ of the daily energy needs of infants (26). In infants aged 11 to 23 months, the daily energy intake requirements defined (24) are $\sim 81 \mathrm{kcal} / \mathrm{kg} /$ day. The mean weights of infants aged 6 to 11 months and 12 to 23 months are 9 and $11 \mathrm{~kg}$, respectively. Consequently, the energy intake requirements for infants aged 6 to 11 months and 12 to 23 months are 711 and $891 \mathrm{kcal} / \mathrm{kg} /$ day, respectively. Precisely, the complementary foods should cover $40 \%$ of this requirement (26). In the present study, the fermented porridge $\mathrm{F} 3$ and the malted porridge $\mathrm{Fg} 3$ covered 30 and $34 \%$ of the intake requirements, respectively in the infants in group 1 aged of 6 to 11 months, and 30 and $39 \%$ in infants in group 2 aged 11 to 23 months. The consumption of F3 and Fg3 allowed for the coverage of $>30$ and $36 \%$ of their daily energy intake requirements, and $>77$ and $95 \%$ of their daily protein intake requirement. Precisely, the malted porridge $\mathrm{Fg} 3$ provided a coverage of more than one third (36\%) of the daily energy intake requirements for children aged 6 to 23 months.

The high sweetness of the high ED malted Fg3 porridge also improved the coverage of the daily energy and nutrient needs of children aged 6 to 23 months. The results indicated that the coverage of the daily energy and nutrient intake requirements was lower for children aged 6 to 8 months. This was due to the nutrient intake requirement of children aged of 6 to 8 months, which was higher than that of infants aged 9 to 23 months and also due to their low stomach capacity and continuous breastfeeding (18). Similar results were also obtained in a previous study (29). Of all the porridges, only the high ED malted porridge $\mathrm{Fg} 3$ provided high coverage as regards the daily energy and mineral intake requirements for infant aged 6 to 23 months. Based on these results, it can be argued that the high ED porridges evaluated in the present study, notably the malted (Fg3) porridge provided a high nutritional and organoleptic potential for the coverage of daily intake requirements for children aged 6 to 23 months.

In conclusion, as demonstrated herein, the amounts of fermented porridge F3 consumed were higher than those of the malted porridge $\mathrm{Fg} 3$ and the low ED porridge G1. Consequently, the children exhibited a greater appreciation for the fermented porridge F3 compared with the malted porridge Fg3 and G1. In addition, the $15 \%$ sucrose in the high ED fermented and malted porridges allowed for a 4-fold increase in the ENI in children aged 6 to 11 months, and a 6-fold increase in children aged 12 to 23 months. The energy and nutrient intake of the high ED malted porridge Fg3 were higher than those of the high ED fermented porridge F3. The lower ED G1 porridge intake was low. In one meal, the consumption of the high ED malted porridge $\mathrm{Fg} 3$ provided the highest coverage of the infant daily requirements. This allowed for the coverage of at least $36 \%$ of the daily energy needs, $95 \%$ of the daily protein needs, $73 \%$ of the daily iron needs, $93 \%$ of the daily zinc needs, $48 \%$ of the daily calcium needs and $109 \%$ of the daily magnesium needs for infants aged 6 to 23 months. Modifications in the taste of porridges by the addition of $15 \%$ of sucrose was associated with an increase in energy and nutrient density, thus leading to an increase in ENI. The children's appetite was assessed by increasing the amount of porridge consumed in one meal. This assessment may not indicate the actual appetite of children for porridges. It is suggested that children's appetite be assessed over a longer period of time for porridge consumption for a better assessment.

\section{Acknowledgements}

The authors are grateful to the Government of Benin for their assistance with the research unit at the Nutrition and Food Science of University of Abomey-Calavi.

\section{Funding}

The present study was sponsored by the Government of Benin, provided by the assistance at the research unit at the Nutrition and Food Science of University of Abomey-Calavi.

\section{Availability of data and materials}

The datasets used and/or analysed during the current study are available from the corresponding author on reasonable request.

\section{Authors' contributions}

SEK performed the analyses and wrote the manuscript. WAH and SB contributed to the design and conception of the study and also supervised the study, and participated in the writing of the manuscript. MMS commented and approved the final manuscript contributing substantially to the work reported and to the analyses. SEK and WAH confirm the authenticity of all the raw data. All authors have read and approved the final manuscript.

\section{Ethics approval and consent to participate}

Local health authorities were informed about the study. For children selected to participate in the study, a consent form was presented and explained to parents (father and mother) in their local language in order to have their verbal and written consent. Mothers also gave their consent to participate in the tasting and appreciation of the infant porridges.

\section{Patient consent for publication}

Not applicable.

\section{Competing interests}

The authors declare that they have no competing interests.

\section{References}

1. Victora CG, Bahl R, Barros AJ, Franca GV, Horton S, Krasevec J, Murch S, Sankar MJ, Walker N and Rollins NC; Lancet Breastfeeding Series Group: Breastfeeding in the 21s century: Epidemiology, mechanisms, and lifelong effect. Lancet 387 : 475-490, 2016. 
2. World Health Organization (WHO): Complementary feeding of young children in developing countries. WHO, Geneva, pp130-131, 2003.

3. Brugaillères $\mathrm{P}$, Issanchou S, Nicklaus S, Chabanet $\mathrm{C}$ and Schwartz C: Caloric compensation in infants: Developmental changes around the age of 1 year and associations with anthropometrics up to 2 years. Am J Clin Nutr 109: 1344-1352, 2019.

4. Brugaillères $P$, Chabanet $C$, Issanchou $S$ and Schwartz $C$ : Combining two observational methods to describe mealtime episodes in mother-infant dyads during complementary feeding. In: Proceedings of the Measuring Behavior 11th International Conference on Methods and Techniques in Behavioral Research, Manchester, 2018.

5. Brown A, Jones SW and Rowan H: Baby-led weaning: The evidence to date. Curr Nutr Rep 6: 148-156, 2017.

6. Bournez M, Ksiazek E, Charles MA, Lioret S, Brindisi MC de Lauzon-Guillain B and Nicklaus B: Frequency of use of added sugar, salt, and fat in infant foods up to 10 months in the nationwide ELFE cohort study: Associated infant feeding and caregiving practices. Nutrients 11: 733, 2019.

7. World Health Organization (WHO): Nutrition: maternal, infant and young child nutrition: draft comprehensive implementation plan: report by the Secretariat. WHO, Geneva, 2012. https://apps. who.int/iris/handle/10665/23742.

8. Institut National de la Statistique et de l'Analyse Economique (INSAE), ICF: Demographic Health Survey of Benin, 2019. INSAE and ICF, Cotonou, Benin and Rockville, MD, p675, 2019.

9. Ategbo EA: Food and nutrition insecurity in northern Benin: impact on growth performance of children and on year to year nutritional status of adults (unpublished $\mathrm{PhD}$ thesis). Wageningen University, 1993.

10. Kouton SE, Amoussa Hounkpatin W, Ballogou VY, Lokonon JH and Soumanou MM: Characterization of the feeding of young children aged 6 to 36 months in rural and urban areas of the South Benin. J Appl Biosci 110: 10831-10840, 2017.

11. Amoussa Hounkpatin W: Evaluation of the potential coverage of vitamin A needs of young children from sauces accompanying staple foods consumed in Benin (unpublished $\mathrm{PhD}$ thesis). University of Montpellier 2, 2011.

12. Lindsay AC, Sitthisongkram S, Greaney ML, Wallington SF and Ruengdej P: Non responsive feeding practices, unhealthy eating behaviors, and risk of child overweight and obesity in Southeast Asia: A systematic review. Int J Environ Res Public Health 14 436, 2017.

13. Kouassi AKA, Agbo EA, Dago AG, Gbogouri AG, Brou DK and Dago G: Comparison of nutritional and rheological characteristics of infant porridges prepared by germination and fermentation process. Int J Biol Chem Sci 9: 944-953, 2015.

14. Songré-Outtara LT, Gorga K, Savadogo A, Bationo F and Diawara B: Evaluation of the nutritional ability of foods used in complementary feeding of young children in Burkina Faso. Journal de la Société Ouest Africaine de Chimie 41: 41-50, 2016.

15. Ponka R, Nankap ELT, Tambe ST and Fokou E: Nutritional composition of some artisanal infant flours from Cameroon. Int J Innovation Appl Studies 8: 280-292, 2016.

16. Trèche S: Complementary foods in developing countries: importance, required characteristics, constraints and potential strategies for improvement. In: Promoting growth and development of under fives: proceedings of the international colloquium. Kolsteren P, Hoerée T and Perez-Cuetoeds (eds). Promoting Growth and Development of Under Fives: International Colloquium, Anvers, pp132-148, 2001.

17. Kouton SE, Amoussa Hounkpatin W, Ballogou VY and Soumanou MM: Nutritional, microbiological and rheological characteristics of porridges prepared from infant flours based on germinated and fermented cereals fortified with soybean. IntJ CurrMicrobiolAppSci 6: 4838-4852, 2017.

18. Vieu MC, Traore T and Trèche S: Effects of energy density and sweetness of gruels on Burkinabe infant energy intakes in free living conditions. Int J Food Sci Nutr 52: 213-218, 2001.

19. Association of Official Analytical Chemists (AOAC): Official Methods of Analysis of AOAC International - 20th Edition. AOAC, Washington DC, pp3-172, 2016.
20. Atwater WO and Benedict FG: Respiration Calorimeter. In: Experiments on the metabolism of matter and energy in the human body, 1900-1902. US Department of Agriculture, Office of Experiment Stations - Bulletin No. 136., 2014. https://www. pftforum.com/history/respiration-calorimeter-1902-atwater-benedict/. Accessed November 12, 2014

21. Zannou Tchoko J, Bouaffou KG, Kouame KG and Konan BA: Evaluation of nutritional value of infant flours based of Manihot esculenta flour and soybean flour for infant in complementary feeding. Consortium of Sciences Society of Liège 80: 748-758, 2011.

22. Food and Agriculture Organization (FAO): Human energy requirements. Report of a joint $\mathrm{FAO} / \mathrm{WHO}$ expert consultation. FAO, Rome, 2001

23. Butte NF: Energy requirements of infants. Public Health Nutr 8 (7A): 953-967, 2005

24. Torun B: Energy requirements of children and adolescents Public Health Nutr 8 (7A): 968-993, 2005.

25. Food and Agriculture Organization (FAO)/World Health Organization (WHO): Vitamin and mineral requirements in human nutrition. Report of a joint $\mathrm{FAO} / \mathrm{WHO}$ expert consultation. 2nd edition. FAO/WHO, Bangkok, 2004.

26. Joint $\mathrm{FAO} / \mathrm{WHO} / \mathrm{UNU}$ Expert Consultation on Protein and Amino Acid Requirements in Human Nutrition (2002: Geneva, Switzerland), Food and Agriculture Organization of the United Nations, World Health Organization and United Nations University: Protein and amino acid requirements in human nutrition: report of a joint $\mathrm{FAO} / \mathrm{WHO} / \mathrm{UNU}$ expert consultation. WHO, Geneva, 2007.

27. Vieira-Dalodé G, Jerpersen L, Hounhouigan J, Moller PL, Nago CM and Jakobsen M: Lactic acid basteria and yeasts associated with 'gowé' production from sorghum in Benin. J Appl Microbiol 103: 342-349, 2007.

28. Ventura AK, Garcia P and Schaffner AA: Associations between bottle-feeding intensity and maternal encouragement of bottle-emptying. Public Health Nutr 20: 3090-3098, 2017.

29. Traoré T, Vieu MC, Traoré AS and Trèche S: Effects of the duration of the habituation period on energy intakes from low and high energy density gruels by Burkinabé infants living in free conditions. Appetite 45: 279-286, 2005.

30. Moursi M, Mbemba F and Trèche S: Does the consumption of amylase-containing gruels impact on energy intake and growth of Congolese infants? Public Health Nutr 6: 249-258, 2003.

31. Dewey KG and Brown KH: Update on technical issues concerning complementary feeding of young children in developing countries and implications for intervention programs. Food Nutr Bull 24: 5-28, 2003.

32. Remy E, Issanchou $\mathrm{S}$, Chabanet $\mathrm{C}$ and Nicklaus $\mathrm{S}$ : Repeated exposure of infants at complementary feeding to a vegetable puree increases acceptance as effectively as flavor-flavor learning as and more effectively than flavor-nutrient learning. J Nutr 143: 194-200, 2013

33. Fogel A, Goh AT, Fries LR, Sadananthan SA, Velan SS, Michael N, Tint MT, Fortier MV, Chan MJ, Toh JY, et al: Faster eating rates are associated with higher energy intakes during an ad libitum meal, higher BMI and greater adiposity among 4.5-year-old children: Results from the growing up in Singapore towards healthy outcomes (GUSTO) cohort. Br J Nutr 117: 1042-1051, 2017

34. Kayodé APP, Hounhouigan DJ, Nout MJR and Niehof A: Household production of sorghum beer in Benin: Technological and socio-economic aspects. Inter $\mathbf{J}$ Consumer Studies 31: 258-264, 2007.

This work is licensed under a Creative Commons Attribution-NonCommercial-NoDerivatives 4.0 International (CC BY-NC-ND 4.0) License. 